\title{
The State of Clinical Librarianship in Canada: a Review of the Literature, 1970-2013'
}

\author{
Helen Halbert
}

\begin{abstract}
This paper examines the history of clinical librarianship in Canada from 1970 to 2013 as seen through the lens of practitioner narratives and published literature. While no reviews of clinical librarianship in Canada were found in the literature search, there were many project descriptions in articles and published reports that have provided insight into the field during its formative period in Canada from the 1970s. In addition to tracing narrative histories from 1970 to 2013, the author has continued to wonder why these important stories have never properly been told. Was it because the scope of clinical librarianship, its expected and embodied professional duties, was not regulated (as it is in the United States and United Kingdom)? Is it because the American Library Association accredited library schools in Canada do not offer appropriate curricula and professional training? It seems clear that some librarians in Canada were pioneers in the way that Gertrude Lamb was in the United States, but they did not call themselves clinical librarians. Consequently, they opted for more generic job titles such as medical librarian and health librarian. Whatever the reasons for this, it is within this framework that the author begins an exploration of clinical librarianship in Canada. The paper's aim is to provide a view into clinical librarianship in Canada back to the 1970 s to ensure the story is properly told.
\end{abstract}

\section{Introduction}

As of 2013, the current state of clinical librarianship in Canada is difficult to characterize. With no extant numbers or inventories of clinical librarians practicing here, there is also no specific interest group in CHLA/ ABSC for clinical librarians. Much of the information about clinical librarianship is available from conference reports and published papers from the JCHLA/JABSC and the Health Information and Libraries Journal. A few case reports and papers have been published by the Journal of the Medical Library Association in the United States but no proper, comprehensive survey of the field has been completed in Canada. Such an oversight is unusual given the pioneering efforts of Canadians such as Joanne Gard Marshall, whose work focused on making information accessible and relevant to health professionals in clinical settings. In 2005, Weightman and Williamson [1] in the United Kingdom published a systematic review of clinical librarianship, and in 2011, a systematic review of clinical librarian services was completed by Brettle et al. [2], but their focus was on the work of librarians in the UK and the United States.

Since Marshall's work in the 1980s, there have been no surveys of the field studies or the few case studies in Canada. It remains to be seen if reference to the field is lacking due to low critical mass or whether it is attributable to the lack of consensus about parameters of the profession [2] or because no single model has been promulgated. In the UK, surveys of practice [3] and a content analysis of job recruitment postings [4] reveal that some confusion persists over what differentiates clinical librarianship from other practices in health librarianship. Based on both informal communications with health librarians and a synthesis of past literature on clinical librarianship, a recent study of North American practice by Tan and Maggio [5] defined clinical librarians as "individuals with a library science degree who, in the context of a patient care team, provide customized services to meet information needs related to patient care...These individuals have responsibilities beyond those of a general hospital librarian and beyond providing traditional reference and document delivery services." Despite the lack of practice of applying a consistent definition to models of clinical librarianship, this description will be adopted for the purposes of this literature review.

The lack of definition is only one obstacle towards true professional recognition in medicine [6] despite the value clinical librarians bring to the clinical team. Moreover, "the establishment of a national clinical librarian profile" [7] is difficult when funding is so unpredictable not just in Canada and the UK, but elsewhere. Professional responsibilities also vary and may change over time, and thus the job title of practicing librarians may not accurately reflect

Helen Halbert ${ }^{2}$. Unit 8, 2465 W. 1st Avenue, Vancouver, BC, V6K 1G5.

${ }^{1}$ This article was the recipient of the 2013 Login Canada Student Paper Prize. This article has been peer reviewed.

${ }^{2}$ Corresponding author (e-mail: Helen.Halbert@gmail.com) 
or account for their clinical outreach. In a 2013 study [5], this was the case for six out of the seven North American health library professionals identified as providing clinical librarian services. Petrinic and Urquhart [8] believe the often short-term nature of many clinical librarianship programs and projects may also prevent the development or articulation of a dedicated clinical librarian posting. If the situation is comparable to that of the UK, broad variations in professional terminology, from informationist to "learning resources services manager" [6], may, to some extent, account for underrepresentation in Canada today.

There are other explanations worth considering. It may be that the low profile of clinical librarians in Canada is a sentinel of some kind, indicating a lack of community of practice. In 2010, one study of clinical librarianship in the UK [6] examined the education, training, workplace, and workload of professionals to determine whether a "definite identifiable" clinical librarianship role exists in the UK and, if so, how it might export to other countries to provide a kind of professional "blue print". Though the study reports on a diversity of qualifications and clinical specialties rather than one clear role, feedback from the librarians' survey indicates that a majority feel "increased use and development of Clinical Guidelines" as well as the promotion of clinical governance within the National Health Service are critical for clinical librarianship to flourish. However, it was less clear how exporting the UK model to other countries would be possible without professional licensing in those jurisdictions.

The challenge of professional standardization could further be exacerbated by a paucity in curriculum devoted to health librarianship with Canadian Master of Library and Information Science (MLIS) programs. While offerings such as the University of British Columbia's LIBR 534 ("Health Information Sources and Services"), Dalhousie University's INFO 6750 ("Health Sciences Literature and Information Sources"), and McGill University's GLIS 671 ("Health Sciences Information") are intended to provide both an introduction to and foundation for health library work, such courses are typically not requirements, and are stand-alone elective classes, rather than part of a directed specialization or stream within the degree. Furthermore, such courses are often held on an irregular basis or on a cycle of alternating academic years, which can be exclusionary for those master students seeking to complete their program of study within a certain timeframe. The University of Western Ontario is exceptional in that it offers a Health/Medical Information "area of concentration" within the MLIS program, as well as a joint graduate program in Health Information Science offered through the Faculty of Information and Media Studies and the Faculty of Health Sciences. To be accepted into the Master of Health Information Science (MHIS) program, students must demonstrate some knowledge or academic background in health. Similarly, at the University of Toronto, some of the health-oriented offerings within the Faculty of Information are cross-listed with courses at the Institute of Health Policy, Management \& Evaluation, which in turn provides a Master of Health Informatics program. While such programs testify to the emerging recognition of the need and value of health information processing and manage- ment, it remains unclear whether it is the role of library and information schools to provide this education, or if health sciences departments are better situated to prepare professionals to work in this field. According to a 2005 survey of Canadian academic health sciences librarians [9], subject expertise is important; however, there are a variety of ways outside of traditional education to acquire the necessary health knowledge including participation in professional associations like the Canadian Health Libraries Association (CHLA) and regular reading of CANMEDLIB, the e-mail discussion list of the CHLA. A 2007 study of the education qualifications of health librarians in the UK suggests that clinical librarians, in particular, may desire and require more structured forms of continuing professional development $[8,10]$.

Two theories of the diffusion and implementation of innovation provide some insight into why the clinical librarian profession has generally little uptake in Canada. The theories suggest that professions are unlikely to thrive within environments where resources, value recognition, and institutional infrastructure are lacking, especially in those situations that do not support or promote a community of practice $[11,12]$. In 1991, one of the icons of Canadian medical librarianship, Frances K. Groen, published "The changing role of the hospital librarian: Canadian and US comparisons" [13]. In the article, she described the changing roles and challenges of hospital librarians and differences in practices in Canada and the United States. While noting that "the practice of our profession, especially within the clinical environment is essentially similar," Groen [13] attributed different approaches to evaluating and delivering health information to the contrasting social values of the two countries (specifically, Canada's commitment to universal health care) and their respective health care economic models. Additional differences Groen identified included geographic and demographic factors, the lack of a Canadian institution equivalent to America's research-oriented $\mathrm{Na}$ tional Library of Medicine, and the lack of a recognition program such as the Academy of Health Information Professionals, which directs continuing education for health librarians in the US. However, the differences between Canada and the US in the development of health librarianship cannot be explained solely by funding and privatization alone. In fact, the UK provides universal health care and is a centrepiece of production for much research about clinical librarianship. While studying the professional practice of health librarianship is seen as important in Groen's writings, this has not been comprehensively demonstrated to date, particularly within a Canadian context.

\section{Methods: studying the narrative}

To examine clinical librarianship as practiced in Cana$\mathrm{da}$, a systematic retrieval of all relevant studies was undertaken in PubMed, CINAHL, LISTA, EMBASE, and Google Scholar, and references in the bibliographies of papers were harvested. Print copies of the Bibliotheca Medica Canadiana (BMC) and BMC's successor, the Journal of the Canadian Health Libraries Association 
(JCHLA) / Journal de l'Association des bibliothèques de la santé du Canada (JABSC) were hand searched from 1976 to the present. While no reviews of clinical librarianship in Canada were found, there were many project descriptions in articles, on Websites, and in published reports that have provided insight into the field during its formative period in Canada from the 1970s.

\section{Results: narrating the studies}

In the 1990s, Canadian health librarian and academic Joanne Gard Marshall initiated several projects to study the impact of hospital libraries in clinical decision-making. In 1978, she completed her Master of Health Sciences (MHSc) thesis entitled "An assessment of the level of medical knowledge of patients with Crohn's disease" [14]. To establish a clinical librarian program, from 1978 to 1982 Marshall concentrated on taking information to the clinic and to the point of care [14] and beyond. One project she was involved with featured collaboration between McMaster University and the Hamilton Public Library to provide patients access to noncirculating materials from the Health Sciences Library [15]. In 1982, the article she wrote describing a randomized trial of librarian educational intervention in clinical settings earned her the Ida and George Eliot Prize from the Medical Library Association. Her groundbreaking work, the Rochester Study, has led to other research In 2013, Marshall updated her study on the value of health libraries in clinical decision-making [16], this time with a focus on the role of the librarian in today's information environment, specifically in providing access to electronic resources. Her contributions to clinical librarianship and the value of clinical librarians in decision-making are central to the field's development [17]. Marshall is a pivotal figure in the history of clinical librarianship, and her work deserves close examination particularly where it pertains directly to Canada.

In 1975, Marshall reported on a clinical librarian project conducted at the McMaster University Medical Centre in Hamilton, Ontario. The Medical Centre consisted of a family practice unit, specialty ambulatory clinic, and a 420bed in-patient facility [18]. As part of the program, a clinical librarian attended morning rounds once a week and returned to the onsite library to perform literature searches for the medical team. The clinical librarian responded to questions and information requests from clinicians and would select articles and share them with others by posting them in the conference room. While the health professionals at McMaster reported positive experiences with the clinical librarian, no formal evaluation of the pilot was performed.

In 1981, Marshall conducted a second study at McMaster University, this time displaying a high degree of methodological rigour [19] by using randomization to compare the information-seeking behaviours of health professionals in two groups: (i) those receiving the help of a clinical librarian and (ii) those that did not receive the help of a clinical librarian [20]. Over a six-month period, the clinical librarian would search and collect information on hot topics, provide library research workshops, and create information packages for patients. Study partici- pants were then surveyed on how likely they were to use the library as a result of the clinical librarian's efforts. By 1993, Marshall set her sights on demonstrating the link between information literacy and the efficient delivery of patient care. She compared the use of the library by medical students at three medical schools in Ontario, namely McMaster University Medical School and those at the universities of Western Ontario and Toronto [21]. Based on health library circulation data and surveys of health library users, the authors concluded that students in problem-based learning (PBL) programs used the library more often and found that total numbers of items borrowed and renewed over two months was five times higher at McMaster (a medical school oriented towards PBL since its founding in 1965) than at Western (which featured one day of PBL study per week) and Toronto (which had yet to introduce PBL). Interestingly, a comparison of the faculty members of the three schools yielded different results for library usage, with one professor from McMaster stating that the "faculty actually used the library less when teaching in a PBL environment, because PBL students were more likely to identify useful sources than students in traditional programs" [21].

In the Bibliomedica Medica Canadiana in 1994, Makowski [22] wrote one of the earliest articles about clinical librarianship in Canada from her perspective as a health librarian. In it, she outlines the development of early clinical librarianship programs. While acknowledging the profession's popularity within the US, Makowski refers to the McMaster program and Marshall, highlighting the model that "emphasized provision of service to nonphysician members of the health care team and also provided service for patients and their families."

In 2005, Watson [9] reported on an online 15-item survey of subject knowledge of health librarians that was sent by e-mail to Canadian academic health librarians. In it, Watson was interested in the national demographic of health librarianship as a whole, thus the questionnaire did not ask for or report on job titles. Furthermore, it did not distinguish between health librarianship and clinical librarianship and relied on questions about qualifications, educational background, and continuing professional development. In a second questionnaire, Polger [23] examined whether any distinction exists between informationist and clinical librarian models and the numbers of hospitals and health centres currently offering these services as of 2009. Polger's 12-question survey included a Canadian component, and it was developed and distributed to health library listservs over a 10-month period in both Canada and the US (MEDLIB-L and CANMEDLIB). That said, the information supplied by health librarians about their type of institution, academic background, and participation in clinical rounds was not analyzed by country. The study does not further our understanding of the Canadian practices of the field.

In 2009, the Canadian team of Elizabeth Aitken et al. [24] conducted a four-week study of the general internal medicine in-patient medical teaching unit in a large tertiary care teaching hospital in Calgary, Alberta. Aitken et al. sought to demonstrate the positive effects of a librarian on clinical rounds with respect to the clinical decision-making 
abilities of medical residents. The study involved a direct comparison between an intervention group that had access to a clinical librarian and a control group that did not. Teams were typically comprised of one attending physician, four residents, two to three final-year medical students, and a pharmacist. The participating librarian possessed an ALA-accredited MLS degree and more than 20 years in health librarianship, which included experience in clinical rounds at another hospital and instruction in evidence-based information retrieval. The librarian spent between 10 and 12 hours per week with the intervention group, providing guidance and teaching how to search for information and did searches on request. The librarian occupied an "anticipatory role" of filling perceived information needs during patient case presentations. Following the intervention, $88 \%$ of participants said they had changed their approach to treatment because of the information skills taught by the clinical librarian. Additionally, there was a reported $10 \%$ increase in participants' willingness to use databases such as the Cochrane Database of Systematic Reviews and EMBASE. The results showed that participants were both receptive to and appreciative of clinical librarians, leading the authors to conclude that the "addition of a clinical librarian to the patient care team is an improvement in process" [24] and is a facilitator of evidence-based medicine. While findings showed that health practitioners received value from the intervention arm, the authors acknowledged that an evaluation of the effect on patient care is needed to corroborate the positive potential of clinical librarianship.

Similarly, Fallis and Shaw-Daigle [25] conducted a pilot study at the Victoria General Hospital in Winnipeg, Manitoba in 2005 and 2006 with the intention of promoting access and use of evidence in health care provision. Over a period of six months from December 2005 to May 2006, the hospital researcher and librarian made themselves available to two acute care units for two 45-minute periods per month. Sessions were held in the staff lounge and scheduled at times that were most convenient for hospital staff. Health professionals were encouraged to consult or discuss their information needs and were provided with a sampling of library resources. Additionally, over the course of the program, the researcher and librarian developed competency packages featuring up-todate information on a variety of evidence-based topics. The results showed that many in the hospital were happy with the service, and that many staff took the time to review resources and some hospital educators requested competency packages. However, few members of staff actually registered for library privileges, leading Fallis and ShawDaigle to conclude that their service could be a key component in raising the library's profile, marketing collections, and promoting evidence-based practices.

At the University of Manitoba Health Sciences Libraries in 2009, Patricia Barrett [7] profiled the creation of an online literature centre by the librarians to serve and support an initiative by the Nursing Leadership Council of the Winnipeg Regional Health Authority. This service specifically targeted the information needs of nurses, and Barret believed the development of such a centre for a nursing leadership program was the first of its kind in the context of Canadian health science libraries or among other commonwealth countries and the United States. The strategies used by the librarians were described, including an exploratory needs assessment and challenges faced by nurses during information retrieval; however, the program has not yet been evaluated. Surprisingly, the outcomes of the project, nurses' reactions, and quality of care were not measured.

In Toronto, a study by Greco et al. [26] that was based out of the Division of General Surgery at the University Health Network provided an introduction of a clinical librarian to the Quality of Care rounds. In 2005, the clinical librarian assisted the surgery team resident responsible for reviewing and reporting back about the literature to solve a clinical case. Greco et al. concluded that the project was useful and the inclusion of a clinical librarian led to "evidence-based reviews by residents that were of higher quality than before" [26]. Similar to Fallis and Shaw-Daigle's conclusions [25], another benefit was the potential of the program to increase awareness of and familiarity with hospital library services. That said, beyond some comments from hospital staff (not self-reports or an administered questionnaire), no evidence was collected or presented to provide support for either claim.

In 2012, Powelson and Reaume [27] evaluated how satisfied physicians and healthcare providers were with a new library service and delivery model provided by the Health Information Network Calgary, which was established through a joint partnership between the University of Calgary and Alberta Health Services Calgary Zone. While not explicitly an evaluation of clinical librarianship services, by distribution of their 18-question satisfaction survey instrument, Powelson and Reaume assessed the impact of library services on patient care, with particular attention to the role of "front-line library staff" as information broker for patient care providers. Of 694 surveys that were returned, $75 \%$ reported that they had used hospital library services, and $43 \%$ indicated that information and resources do "contribute to better patient care decisions" [27]. This impact was self-reported, and thus is a limitation of the study. While the authors acknowledge the survey's shortcomings, they argue for generalizability of their findings by citing the Donabedian model of quality of care which "predicts that an improved process will lead to improved care" [27], something they assert is provided by the new service model.

In 2013, Tan and Maggio [5] interviewed six clinical librarians from Canada, and one from the US, to determine what roles and responsibilities they typically performed on a day-to-day basis. All participants worked at university-affiliated teaching hospitals and reported on a range of activities including literature searching and fielding reference questions from patients. Participants often fulfilled an instructional role, teaching clinicians on topics as varied as reference management and copyright policy. Tan and Maggio reasoned that, in light of the sample's bias towards librarians from teaching hospitals, this was perhaps not an unusual finding. On the other hand, they concluded that, given clinical librarians' expertise in content management, it was notable that none of the participants' workloads included maintenance 
of electronic health records (EHRs) or involvement in EHR projects, an area that has previously been identified as one that could benefit from the participation of Canadian health librarians [28].

\section{Conclusions: giving voice to stories}

According to the available literature, there are a number of clinical librarianship and health librarianship programs currently in support of evidence-based practice in a variety of locales across Canada. The creation of the electronic open-access journal, Evidence-Based Library and Information Practice, by a group of Canadian librarians is an indication of an important community committed to the principles of evidence-based practice and involved in professional capacity-building initiatives that encourage librarians to pursue research and apply findings to work approaches, collection development, outreach efforts, and service delivery. While each of the studies in this review provides a glimpse into the arc of history, the picture is only a fuzzy snapshot of highlights and not a true historical survey.

Future longitudinal studies are needed that can more closely evaluate the long-term impact of clinical librarianship from the early Marshall studies, using a wide range of metrics. Although the survey distributed in her replication of the Rochester Study [16] strategically employed critical incident technique to elicit responses about patient care, the research was planned [29] and conducted with particular attention to the role of the library and librarian in light of technological change and evolving informationseeking practices. Furthermore, the survey responses assessed the perspectives of health professionals, rather than the experiences of patients. The impact of clinical librarians in the delivery of patient care [30] and education was identified by Marshall several decades ago, and it should be revisited perhaps with the author herself. Some of the early pioneers within CHLA/ABSC could be identified and interviewed about this topic as a phenomenological study.

A good starting point may be the study of limitations expressed in previous research and the challenges reported by hospitals in implementing clinical librarian programs. Despite the careful and considered planning that went into Marshall's updated study, including an emphasis on participatory design and a commitment to recruit participants from diverse library settings, Marshall et al. [16] noted that poor administrative and institutional support, as well as library staff time constraints, had a negative effect on participation in the study, even in cases of high interest. Reports on attempts by hospitals [31] to introduce and establish new clinical librarianship programs, a much greater undertaking than study participation and retention, suggest that similar factors work against the practice and continuance of clinical librarianship. While authors are quick to question the generalizability of their own research results and to acknowledge the limitations of a study conducted in a single sample or setting [30], multisite studies that seek to assess the impact of the health library impact have yet to relate findings to contextual factors of practice. Improved documentation and classification of contextual factors influencing the success or failure of clinical librarianship programs would better our understanding of clinical librarianship within Canada as well as inform future planning and pilots of health library services.

A comprehensive survey of CHLA/ABSC members and subscribers to the CANMEDLIB listserv should be conducted about the provision of library services at the frontlines of patient care in Canada's hospitals and clinics. The survey should develop a purposive survey of those health librarians whose position titles, training, day-to-day responsibilities, and place of work identify them as performing clinical librarianship support for clinicians. Once identified, a follow-up study could seek to develop profiles of clinical librarianship according to educational programs and degrees to make recommendations to inform Canadian post-secondary curriculum development that best supports the recruitment and retention of qualified, prepared clinical librarian professionals. Armed with this information, the Canadian health library community could more accurately account for the work of clinical librarians and the important work they do for the betterment of Canada's health care system.

\section{References}

1. Weightman AL, Williamson J. The value and impact of information provided through library services for patient care: a systematic review. Health Info Libr J. 2005;22(1):4-25. doi:10.1111/j.1471-1842.2005.00549.x.

2. Brettle A, Maden-Jenkins M, Anderson L, McNally R, Pratchett T, Tancock J, Thornton D, Webb A. Evaluating clinical librarian services: a systematic review. Health Info Libr J. 2011;28(1):3-22. doi:10.1111/j.1471-1842.2010. 00925.x.

3. Ward L. A survey of UK clinical librarianship: February 2004. Health Info Libr J. 2005;22(1):26-34. doi:10.1111/ j.1471-1842.2005.00556.x.

4. Sargeant SJ, Harrison J. Clinical librarianship in the UK: temporary trend or permanent profession? Part I: a review of the role of the clinical librarian. Health Info Libr J. 2004;21(3):173-81. doi:10.1111/j.1471-1842.2004.00510.x.

-5. Tan MC, Maggio LA. Expert searcher, teacher, content manager, and patient advocate: an exploratory study of clinical librarian roles. J Med Libr Assoc. 2013;101(1):6372. doi:10.3163/1536-5050.101.1.010.

6. Harrison J, Beraquet V. Clinical librarians, a new tribe in the UK: roles and responsibilities. Health Info Libr J. 2010;27(2):123-32. doi:10.1111/j.1471-1842.2009.00862.x.

7. Barrett P. An online nursing leadership literature centre at the University of Manitoba Health Sciences Libraries. Health Info Libr J. 2009;26(3):232-9. doi:10.1111/j.14711842.2008.00828.x.

8. Petrinic T, Urquhart C. The education and training needs of health librarians - the generalist versus specialist dilemma. Health Info Libr J. 2007:24(3):167-76. doi:10.1111/j.14711842.2007.00717.x.

9. Watson EM. Subject knowledge in the health sciences library: an online survey of Canadian academic health sciences librarians. J Med Libr Assoc. 2005;93(4):459-466. 
10. Sargeant SJ, Harrison J. Clinical librarianship in the UK: temporary trend or permanent profession? Part II: present challenges and future opportunities. Health Info Libr J. 2004;21(4):220-6. doi:10.1111/j.1471-1842.2004.00541.x.

11. Damschroder LJ, Aron DC, Keith RE, et al. Fostering implementation of health services research findings into practice: a consolidated framework for advancing implementation science. Implement Sci [serial online]. 2009; 4:50. Available from: http://www.implementationscience.com/ content $/ 4 / 1 / 50$

12. Greenhalgh T. How to read a paper: the basics of evidencebased medicine. 2nd ed. London, (UK): BMJ Books; 2001.

13. Groen F. The changing role of the hospital librarian: Canadian and US comparisons. Bibliotheca Medica Canadiana. 1991;12(3):144-150.

14. Fitzgerald D. Joanne Gard Marshall, AHIP, FMLA Medical Library Association President 2004-2005. J Med Libr Assoc. 2004;92(3):302-305.

15. Marshall JG. Clinical librarians join health care team to provide information directly. Can Lib J. 1979;36(1-2):23-8.

16. Marshall JG, Sollenberger J, Easterby-Gannett S, et al. The value of library and information services in patient care: results of a multi-site study. J Med Libr Assoc. 2013; 101(1):39-46. doi:10.3163/1536-5050.101.1.007.

17. Marshall JG. Measuring the value and impact of health library and information services: past reflections, future possibilities. Health Info Libr J. 2007;24 Suppl 1:4-17. doi:10.1111/j.1471-1842.2007.00750.x.

18. Marshall JG, Hamilton JD. The clinical librarian and the patient: report of a project at McMaster University Medical Centre. Bull Med Libr Assoc. 1978;66(4):420-5.

19. Eldredge J. Do Clinical Librarians Matter? The first randomized controlled trial in librarianship. Evid Based Libr Inf Pract [serial online]. 2007; 2(4). Available from: http:// ejournals.library.ualberta.ca/index.php/EBLIP/article/view/ 719

20. Marshall JG, Neufeld VR. A randomized trial of librarian educational participation in clinical settings. $J$ Med Educ. 1981;56(5):409-16.
21. Marshall JG, Fitzgerald D, Busby L, et al. A study of library use in problem-based and traditional medical curricula. Bull Med Libr Assoc. 1993;81(3):299-305.

22. Makowski G. Clinical medical librarianship: a role for the future. Bibliotheca Medica Canadiana. 1994;16(1):7-13.

23. Polger MA. The Informationist: Ten Years Later. J Hospital Librariansh. 2010; 10(4): 363-379. doi:10.1080/15323269. 2010.514556 .

24. Aitken EM, Powelson SE, Reaume RD, et al. Involving clinical librarians at the point of care: results of a controlled intervention. Acad Med. 2011;86(12):1508-12. doi:10.1097/ ACM.0b013e31823595cd.

25. Fallis W, Shaw-Daigle C. Take 5: Bringing research and library services to front-line staff in a community hospital. Can Nurse. 2007;103(7):10-1.

26. Greco E, Englesakis M, Faulkner A, et al. Clinical librarian attendance at general surgery quality of care rounds (Morbidity and Mortality Conference). Surg Innov. 2009; 16(3):266-9. doi:10.1177/1553350609345487.

27. Powelson SE, Reaume RD. Using the results of a satisfaction survey to demonstrate the impact of a new library service model. Health Info Libr J. 2012;29(3):223-32. doi:10.1111/ j.1471-1842.2012.00988.x.

28. Barron S, Manhas S. Electronic health record (EHR) projects in Canada: participation options for Canadian health librarians. J Can Health Lib Assoc. 2011;32(3):137-43. doi:10.5596/ c11-044.

29. Dunn K, Brewer K, Marshall JG, Sollenberger J. Measuring the value and impact of health sciences libraries: planning an update and replication of the Rochester study. J Med Lib Assoc. 2009;97(4):308-12. doi:10.3163/1536-5050.97.4.016.

30. Marshall JG, Haynes RB. Patient education and health outcomes: implications for library service. Bull Med Libr Assoc. 1983;71(3):259-62.

31. Trojan B. Out of the library and into the ward: clinical librarianship programmes at University Health Network. Proceedings of the European Association for Health Information \& Libraries Workshop; 2007 Sept 12-15; Krakow, Poland. pp. 1-10, available from http://www.bm.cm-uj. krakow.pl/Conferences/EAHIL/ 